\title{
Two Years Profile of Anemia in Systemic Lupus Erythematosus Patients at West Java's Top Referral Hospital, Indonesia
}

\author{
Stefanie Yuliana Usman, ${ }^{1}$ Laniyati Hamijoyo, ${ }^{2}$ Anna Tjandrawati ${ }^{3}$ \\ ${ }^{1}$ Faculty of Medicine Universitas Padjadjaran, ${ }^{2}$ Department of Internal Medicine Faculty of \\ Medicine Universitas Padjadjaran/Dr. Hasan Sadikin General Hospital Bandung, ${ }^{3}$ Department \\ of Clinical Pathology Faculty of Medicine Universitas Padjadjaran/Dr. Hasan Sadikin General \\ Hospital Bandung
}

\begin{abstract}
Background: Anemia is a common clinical manifestation in Systemic Lupus Erythematosus (SLE) patients. Anemia can be caused by an ineffective hematopoietic process or excessive red blood cell destruction. The aim of this study was to classify and characterize anemia in SLE patients.

Methods: This study involved 97 outpatients visiting the Rheumatology Clinic of Dr. Hasan Sadikin General Hospital Bandung, from January 2013 to September 2014. Patient data was collected from medical records and study subjects were selected according to the American College of Rheumatology 1997 criteria for SLE, and the characteristic of anemia among outpatients were described according to the World Health Organization criteria.

Results: The characteristics among 97 respondents showed 95 (98\%) were female; 32 (33\%) were 21-30 years old; and 49 (51\%) had SLE for 1-5 years. The characteristics and classification of anemia, 57 (59\%) had normocytic normochromic, and 33 (34\%) had microcytic hypochromic anemia. According to the severity classification, $48(50 \%)$ had moderate anemia, only $8(8 \%)$ had severe anemia. Four (4\%) subjects had anemic conjunctiva, $45(46 \%)$ had fatigue and $48(50 \%)$ had no clinical manifestations of anemic conjunctiva and fatigue.
\end{abstract}

Conclusions: Moderate anemia, normocytic normochromic anemia are the most prevalent among the subjects. Half of the anemic SLE patient has no clinical manifestation of anemic conjunctiva and fatigue.

Keywords: Anemia, anemic conjuctivasystemic lupus erythematosus, fatigue

\section{Introduction}

Systemic Lupus Erythematosus (SLE) is an autoimmune disease involving multi-organ systems, with cases including females who outnumbered their male counterparts by 9-15:1., ${ }^{1,2}$ A study of lupus patients in Asian populations in 2010 reported that the prevalence of this disease was 30-50/100,000 population. ${ }^{3}$ At the Rheumatology Clinic of Dr. Hasan Sadikin General Hospital Bandung as the top referral hospital in West Java, lupus patients accounted for 291 patients or about $10.5 \%$ from all outpatients in 2010 and 366 patients or about $9.07 \%$ from all outpatients (4,037 patients) in $2011 .{ }^{4}$

Clinical manifestations of SLE vary among individuals, but the most common manifestation is anemia, found in $50 \%$ of SLE patients. ${ }^{5}$ Anemia is a condition in which an insufficient number of red blood cells is present to meet the body's physiological needs for tissue metabolism. ${ }^{6}$ Anemia can be classified based on the World Health Organization (WHO) criteria according to its severity using hemoglobin level or Red Blood Cell morphology as determined by red cell indices such as mean cell volume (MCV), and mean corpuscular hemoglobin (MCH) ${ }^{6,7}$

The most common causes of anemia in SLE are anemia in chronic disease (ACD), irondeficiency anemia (IDA), and autoimmune hemolytic anemia (AIHA), while drug-induced anemia and renal failure anemia are not uncommon. ${ }^{8}$ A study in Malang, Indonesia9 reported that anemia was found in $71.4 \%$ of all

Correspondence: Stefanie Yuliana Usman, Faculty of Medicine, Universitas Padjadjaran, Jalan Raya Bandung-Sumedang Km.21, Jatinangor, Sumedang, Indonesia, Phone: +6281220828205 Email: stefanie_yuliana@yahoo.com 
SLE patients, yet such data was not available at Hasan Sadikin General Hospital Bandung which is the primary/top referral hospital for SLE cases in West Java.

The aim of this study was to describe the characteristics and classification of anemia based on its severity and manifestations.

\section{Methods}

This observational descriptive study utilized a cross-sectional approach and was carried out at the Rheumatology Clinic of Dr. Hasan Sadikin General Hospital Bandung from January 2013 to September 2014. The object of this study was medical records of all SLE outpatients with manifestations of anemia. The aim and the method of the study were approved by the Health Research Ethics Committee, Faculty of Medicine, Universitas Padjadjaran/ Dr. Hasan Sadikin General Hospital Bandung. Data collection was conducted using nonprobability quota sampling with $10 \%$ precision. A minimum of 79 samples was required.

Furthermore, SLE outpatients were evaluated according to the American College of Rheumatology criteria which define systemic lupus erythematosus patients as having at least 4 of 11 SLE diagnostic criteria such as, butterfly/malar rash, discoid rash, oral ulcers, photosensitivity, arthritis, serositis, hematologic disorder, neurologic disorder, immunologic disorder, renal disorder and positive antinuclear antibody (ANA). Patients should have fulfilled the ACR 1997 criteria to be included in this study. Patients with incomplete medical record were excluded from the study. Anemia was classified based on the WHO criteria according to its severity using hemoglobin level (Table 1). ${ }^{6}$

Using the red cell indices (MCV, MCH and $\mathrm{MCHC}$ ), the anemia was then classified as normocytic normochromic anemia, microcytic hypochromic anemia, or macrocytic anemia. MCV was used to determine the red blood cell's size, normal range for MCV is $80-100 \mathrm{fL}$. This MCV measurement can classify anemia into microcytic anemia (MCV below normal range) which can be found in anemia due to iron deficiency, normocytic anemia (MCV within normal range) which can be found in anemia chronic disease, and macrocytic anemia (MCV above normal range) which can be found in hemolytic anemia, nutritional anemia and pernicious anemia. $\mathrm{MCH}$ and $\mathrm{MCHC}$ reflect the hemoglobin content of erythrocytes. The normal range for $\mathrm{MCH}$ is 27-31pg and normal range for $\mathrm{MCHC}$ is $32-36 \%$. Anemia can be classified as normochromic anemia (MCH within normal range) and hypochromic anemia ( $\mathrm{MCH}$ below normal range). $\mathrm{MCH}$ only increases in case of spherocytosis anemia or hemolytic anemia.

The presence of a renal disorder in patients and henceforth, its severity (CKD stage) were determined accordingly using creatinine and ureum measurements. All of these tests were taken from the patient's final laboratory workup. The patient's characteristics such as sex, age, date of diagnosis, renal disorder and CKD stage, type and amount of drugs consumed were collected from the patient's medical record. Outpatients with any missing data were excluded from this study. Ninetyseven outpatients with anemia from January 2013-September 2014 were included in the study; all of them met the inclusion criteria. The collected data were analyzed and presented using frequency tabulation in tables.

\section{Results}

The demographics of the study population showed that out of 97 patients, 95 (98\%) were female. The study subjects' age were between 15-55 years which is the reproductive active age. Patients aged between 21-30 (33\%) were

Table 1 WHO Classification of Anemia

\begin{tabular}{|c|c|c|c|}
\hline & \multicolumn{2}{|c|}{$\begin{array}{c}\text { Female } \\
(>15 \text { years old })\end{array}$} & \multirow{2}{*}{$\begin{array}{c}\text { Male } \\
\text { (>15 years old })\end{array}$} \\
\hline & Non pregnant & Pregnant & \\
\hline Non-anemia & $\geq 12 \mathrm{~g} / \mathrm{dl}$ & $\leq 11 \mathrm{~g} / \mathrm{dl}$ & $\geq 13 \mathrm{~g} / \mathrm{dl}$ \\
\hline Mild anemia & $11-11.9 \mathrm{~g} / \mathrm{dl}$ & $10-10.9 \mathrm{~g} / \mathrm{dl}$ & $11-12.9 \mathrm{~g} / \mathrm{dl}$ \\
\hline Moderate anemia & $8-10.9 \mathrm{~g} / \mathrm{dl}$ & $7-9.9 \mathrm{~g} / \mathrm{dl}$ & $8-10.9 \mathrm{~g} / \mathrm{dl}$ \\
\hline Severe anemia & $<8 \mathrm{~g} / \mathrm{dl}$ & $<7 \mathrm{~g} / \mathrm{dl}$ & $<8 \mathrm{~g} / \mathrm{dl}$ \\
\hline
\end{tabular}


Table 2 Systemic Lupus Erythematosus with Anemia Patient Demography

\begin{tabular}{|c|c|c|}
\hline Characteristics & Frequency (n) & Percentage (\%) \\
\hline \multicolumn{3}{|l|}{$\operatorname{Sex}(N=97)$} \\
\hline Female & 95 & 98 \\
\hline Male & 2 & 2 \\
\hline \multicolumn{3}{|l|}{ Age (years old) $(\mathrm{N}=97)$} \\
\hline $15-20$ & 15 & 15 \\
\hline $21-30$ & 32 & 33 \\
\hline $31-40$ & 28 & 29 \\
\hline $41-50$ & 18 & 19 \\
\hline $51-55$ & 3 & 3 \\
\hline$>55$ & 1 & 1 \\
\hline \multicolumn{3}{|l|}{ Date of Diagnosis (years) $(\mathrm{N}=97$ ) } \\
\hline$<1$ & 2 & 2 \\
\hline $1-5$ & 49 & 51 \\
\hline$\geq 5-10$ & 36 & 37 \\
\hline$\geq 10$ & 10 & 10 \\
\hline \multicolumn{3}{|l|}{ Renal Disorder (N=97) } \\
\hline Yes & 57 & 59 \\
\hline No & 40 & 41 \\
\hline \multicolumn{3}{|l|}{ Stage of CKD (N=57) } \\
\hline Stage 1 & 25 & 44 \\
\hline Stage 2 & 12 & 21 \\
\hline Stage 3 & 13 & 23 \\
\hline Stage 4 & 2 & 3 \\
\hline Stage 5/ ESRD & 5 & 9 \\
\hline \multicolumn{3}{|l|}{ Drugs consumed (N=97) } \\
\hline \multicolumn{3}{|l|}{ Steroid } \\
\hline Methylprednisolone & 91 & 94 \\
\hline \multicolumn{3}{|l|}{ Non steroid } \\
\hline Azathioprine & 28 & 29 \\
\hline Chloroquine & 42 & 43 \\
\hline Cyclophosphamide & 5 & 5 \\
\hline Methrotrexate & 4 & 4 \\
\hline No drugs consumed & 5 & 5 \\
\hline \multicolumn{3}{|l|}{ Type of drugs consumed ( $\mathrm{N}=92)$} \\
\hline Steroid & 32 & 33 \\
\hline Non steroid & 1 & 1 \\
\hline Steroid and non steroid & 59 & 61 \\
\hline \multicolumn{3}{|l|}{ Type of anemia (N=97) } \\
\hline Normocytic hypochromic & 3 & 3 \\
\hline Microcytic hypochromic & 33 & 34 \\
\hline Macrocytic & 4 & 4 \\
\hline Normocytic Normochromic & 57 & 59 \\
\hline
\end{tabular}


Table 3 Classification of Anemia Based on Its Severity

\begin{tabular}{lcc}
\hline \multicolumn{1}{c}{ Severity of Anemia } & Frequency (n) & Percentage (\%) \\
\hline Mild Anemia & 41 & 42 \\
Moderate Anemia & 48 & 50 \\
Severe Anemia & 8 & 8 \\
Total & 97 & 100 \\
\hline
\end{tabular}

Table 4 Distribution of Clinical Manifestation of SLE in Anemia Patients

\begin{tabular}{lcc}
\hline \multicolumn{1}{c}{ Clinical Manifestation } & Frequency (n) & Percentage (\%) \\
\hline Anemic Conjunctiva & 4 & 4 \\
Easily fatigue & 45 & 46 \\
\hline
\end{tabular}

largest in number, followed by those aged between 31-40 (29\%) (Table 2).

Each subject had a different disease chronicity that could be seen from the date of diagnosis. More than half of the patients (51\%) had been diagnosed with SLE from 1-5 years. Renal disorder was encountered in more than half of the subjects (59\%). From data collected, some patients with renal disorder (44\%) had CKD stage 1.

Most of study subjects (95\%) received drugs therapy and only 5 subjects were not taking any drugs. Methylprednisolone, the first-choice drug for SLE therapy, was consumed by more than $90 \%$ of subjects. In general, subjects received steroid and non steroid drugs. Fifty-nine subjects $(61 \%)$ took two types of drugs. Additionally, normocytic normochromic anemia was found in 59\% of subjects, followed by microcytic hipochromic anemia in $34 \%$ of subjects.

Hemoglobin levels were used to assess the severity of anemia as stated by the WHO criteria (Table 1). Moderate anemia was found in half of the subjects, closely followed by mild anemia (42\%). Therefore, the majority of SLE patients at Hasan Sadikin General Hospital Bandung exhibited mild to moderate anemia.

Based on physical examination results of the medical records, a few subjects presented anemic conjunctiva (Table 3). Complaints of being "easily fatigued" were found in less than half of the subjects (Table 4).

\section{Discussion}

The distribution of clinical manifestations of SLE in anemia patients clearly demonstrated that the majority of SLE patients with anemia were female between 21-30 years old, right at the peak of her reproductive age (Table 1 ). Furthermore, female to male ratio was 47.5:1. Such results corresponded relatively well with other studies which stated that the majority of SLE patients were female, the female to male ratio was 9-14:1, but Lopez et al. ${ }^{10}$ reported female to male ratio was up to 50:1 in Spain. The majority of SLE patients were female, this was well suited with the study that stated the effect from reproductive hormone endogenous activity on immune system. ${ }^{11}$ Also, SLE patients were in productive age with their average age was 28-43 years. ${ }^{8,11}$ More than fifty percent of the subjects had been diagnosed with SLE for 1-5 years and more than thirty percent for 5-10 years. Thus, it is no surprise that the majority of SLE patients had anemia due to chronic disease ${ }^{5,8}$

Moreover, renal disorders were found in more than half of the subjects (59\%), in the long run wouldl aid in the precipitation of anemia. The anemia manifests as the kidney's ability to produce erythropoietin, a hormone crucial for red blood cell formation, is severely hampered. ${ }^{12}$ Interestingly, this study demonstrated that most subjects with a renal disorder were at CKD stage 1 , which could have been explained by the timely administration of pharmacotherapy.

In general, most subjects were given a steroid and an immunosuppressant drug. The co-administration of multiple drugs was appropriate as it follows the recommendations for therapy concerning SLE patients, in which steroid as the first-line drug should be administered with complementary drugs (azathiophrine,cloroquine,cyclophosphamide, and methrotrexate) in order to minimize the 
side effects of steroid use. ${ }^{4}$

A majority of subjects exhibited normocytic normochromic anemia (59\%) and such observation is suggestively due to anemia of a chronic disease. A smaller proportion of subjects (34\%) exhibited a different type of anemia (microcytic hypochromic anemia) and such finding is most likely due to irondeficiency. Portillo et al. $^{13}$ reported most patients with chronic disease in Spain have normocytic normochromic anemia, while Thomas et al. ${ }^{14}$ stated that iron deficiency causes microcytic hypochromic anemia to patients in Germany. ${ }^{13,14}$ Nevertheless, it is not uncommon for anemia in SLE to manifest due to both chronic disease and IDA simultaneously. ${ }^{5}$

This study also revealed that most subjects had either moderate anemia (50\%) or mild anemia (42\%). This corresponds well to other studies which often report mild-moderate anemia in SLE patients. ${ }^{15}$ However, the findings of moderate anemia is also justified, taking into account the concurrence of both anemia due to chronic disease and irondeficiency. ${ }^{5}$ Besides anemia chronic disease is caused by several mechanisms, such as iron homeostasis disorder due to cytokines and reticuloendothelial system cells, decrease erythropoietin production due to renal injury or antiproliferative effect from uremic toxin deposition. ${ }^{16}$

Moreover, only 4 (4\%) SLE patients had clinical manifestations of anemic conjunctiva, while $45(46 \%)$ patients complained of fatigue (Table 3). Clinical manifestations of anemia cannot be used to pin point the specific condition of anemia, anemic conjunctiva cannot describe the patient's condition and severity of anemia spesifically because anemic conjunctiva is more obvious in severe anemia patient. ${ }^{17}$ Fatigue is a symptom of several diseases. While anemia is a common cause of fatigue, however fatigue does not reflect severity of the patient's anemia. Fatigue can be caused by psychological factors. ${ }^{18,19}$

However, the study is not without limitations. The medical record only contained information pertaining to the severity of anemia as determined by the RBC indices and there was no record of patients having received Coombs test, reticulocyte count or peripheral blood count. Thus, the information on the possibilty of hemolytic anemia was lacking. ${ }^{20}$ Hence, determining whether the patients were in remission or had had flares was not feasible. Furthermore, the medical record was lacking in the description of anemia-related clinical manifestations other than anemic conjunctiva and fatigue.

For further studies, the authors suggest the need for special attention to patients with chronic SLE or with impaired renal function about the patient's anemia with recorded clinical manifestations of anemia in patients and routine laboratory tests. Education of patients for a routine control about the condition of the disease is also important so that patients can avoid the possible occurrence of complications.

As conclusion, the characteristics of majority of SLE patients are female (98\%), between 21-30 years old (33\%), have been diagnosed with SLE for $1-5$ years $(51 \%)$, exhibited normocytic normochromic anemia (59\%), and had moderate anemia (50\%). Other characteristics are found such as patients have renal disorder $(59 \%)$, and have been given steroid drugs (94\%). Half of the patients have no clinical manifestations of anemic conjunctiva and fatigue.

\section{References}

1. Tsokos GC. Systemic lupus erythematosus. N Engl J Med. 2011;365(2):2110-21.

2. Xiong W, Lahita RG. Pragmatic approaches to therapy for systemic lupus erythematosus. Nat Rev Rheumatol. 2014;10(2):97-107.

3. Salido 0, Reyes M. Epidemiology of systemic lupus erythematosus in Asia. Lupus. 2010;19(12):1365-73.

4. Yoga K I, Kusworini H, Linda KW, Laniyati H, Zuljasri A, Handono K, Hermansyah, et al. Rekomendasi perhimpunan reumatologi Indonesia untuk diagnosis dan pengelolaan lupus eritematosus sistemik. Perhimpunan Reumatologi Indonesia; 2011.

5. Karpouzas GA. Hematologic and lymphoid abnormalities in SLE. In: Wallace DJ, Hahn Bevra H, Isernberg D, Shen N, Vollenhoven $\mathrm{RF}$, Weisman MH, et al, editors. Dubois' lupus erythematosus and related syndromes. $8^{\text {th }}$ ed. Philadelphia: Saunders Elsevier; 2013. p. 426-9.

6. WHO. Haemoglobin concentrations for the diagnosis of anaemia and assessment of severity. 2011 [cited 2014 Februari 09]. Available from: http://www.who. int/vmnis/indicators/haemoglobin/en/ index.html.

7. Sultan AH. Anemia among female college students attending the University of Sharjah, UAE: prevalence and classification. J Egypt Public Health Assoc. 2007;82(34):261-71. 
8. Giannouli S, Voulgarelis M, Ziakas PD, Tzioufas AG. Anaemia in systemic lupus erythematosus: from pathophysiology to clinical assessment. Ann Rheum Dis. 2006;65(2):144-8.

9. Kusworini H, Leny P, Achmad R, Singgih W, Handono K. Vitamin D serum level and disease activity in patients with systemic lupus erythematosus. Int J Pharm Sci Invent. 2013;2(2):35-40.

10. Lopez P, Mozo L, Gutierrez C, Suarez A. Epidemiology of systemic lupus erythematosus in a northern Spanish population: gender and age influence on immunological features. Lupus. 2003;12(11):860-5.

11. Murphy G, Isenberg D. Effect of gender on clinical presentation in systemic lupus erythematosus. Rheumatology. 2013;52(12):2108-15.

12. Jelkmann W. Regulation of erythropoietin production. J Physiol. 2011;589(Pt 6):1251-8.

13. Portillo K, Belda J, Anton P, Casan P. High frequency of anemia in COPD patients admitted in a tertiary hospital. Rev Clin Esp. 2007;207(8):383-7.
14. Thomas C, Thomas L. Anemia of chronic disease: pathophysiology and laboratory diagnosis. Lab Hematology. 2005;11(1):14-23.

15. Zarychanski R, Houston DS. Anemia of chronic disease: a harmful disorder or an adaptive, beneficial response? Can Med Assoc J. 2008;179(4):333-7.

16. Weiss G, Goodnough LT. Anemia of chronic disease. N Engl J Med. 2005;352(10):101123.

17. Butt Z, Ashfaq U, Sherazi SFH, Jan NU, Shahbaz U. Diagnostic accuracy of "pallor" for detecting mild and severe anaemia in hospitalized patients. J Pak Med Assoc. 2010;60(9):762-65.

18. Patel V, Kirkwood B, Weiss H, Pednekar S, Fernandes J, Pereira B. Chronic fatigue in developing countries: population based survey ofwomen in India. BMJ. 2005;330(7501):1190-97.

19. Gasche C, Lomer MCE, Cavill I, Weiss G. Iron, anaemia, and inflammatory bowel diseases. Gut. 2004;53(8):1190-97.

20. Dhaliwal G, Cornett PA, Tierney JrLM. Hemolytic anemia. Am Fam Phys. 2004;69(11):2599-606. 